\title{
COST-EFFECTIVENESS ANALYSIS OF DIRECTLY OBSERVED THERAPY FOR TUBERCULOSIS AND ITS EXPANSION IN RIO DE JANEIRO
}

\author{
ANA CAROLINA MACHADO RUSSO DE MOURA ${ }^{1}$, GABRIELA BITTENCOURT GONZALEZ MOSEGUI ${ }^{1}$, CID MANSO DE \\ MELLO VIANNA ${ }^{2}$, BENEDITO CARLOS CORDEIRO ${ }^{1}$
}

\begin{abstract}
1Professional Master's Degree in Pharmaceutical Care Management, Fluminense Federal University (Universidade Federal FluminenseUFF), Brazil, ${ }^{2}$ Social Medicine Institute (Instituto de Medicina Social), Rio de Janeiro State University, Brazil Email: gabrielamosegui@uol.com.br
\end{abstract}

Received: 03 Jul 2017 Revised and Accepted: 31 Aug 2017

\begin{abstract}
Objective: Brazil is one of the countries with the largest number of cases of tuberculosis worldwide. Rio de Janeiro exhibits some of highest mortality and incidence rates in the country. The aim of the present study was to perform a cost-effectiveness analysis of directly observed therapy (DOT) and simulate its expansion for new cases of pulmonary tuberculosis in Rio de Janeiro.
\end{abstract}

Methods: A decision tree was plotted that simulated the progression of the disease for six months. In the cost-effectiveness analysis, strategies of self-administered treatment (SAT) and DOT (directly observed therapy) with $100 \%$ coverage were compared; the current coverage, $48 \%$, and coverage of $100 \%$ were considered with regard to expansion. The study was based on the epidemiological pattern of tuberculosis in Rio de Janeiro among adults from both genders and without economic differences; the government perspective was adopted. The outcomes were varied to investigate the occurrence of parametric sensitivity.

Results: Although the cost of treatment was increased by three times, DOT proved to be cost-effective for the treatment of new cases, with an incremental cost-effectiveness ratio (ICER) of BRL 30,454 per saved life. Expansion of DOT coverage would avert 180 deaths and 171 instances of treatment dropout, in addition to providing an incremental 420 instances of cure, with an investment of approximately BRL 6,700,000.00.

Conclusion: DOT might contribute to improving the current tuberculosis situation in the state of Rio de Janeiro. Its expansion would fit with the resources estimated by the Brazilian government needed to combat non-drug-resistant tuberculosis.

Keywords: Tuberculosis, Directly Observed Therapy, DOT, Cost-Effectiveness Analysis, Healthcare Assessment

(c) 2017 The Authors. Published by Innovare Academic Sciences Pvt Ltd. This is an open-access article under the CC BY license (http://creativecommons.org/licenses/by/4.0/) DOI: http://dx.doi.org/10.22159/ijpps.2017v9i10.21099

\section{INTRODUCTION}

Tuberculosis is a re-emerging disease that represents a serious public health problem. Despite antibiotic therapy and the formulation of specific policies for treatment, control and prevention, tuberculosis was the main cause of death due to infectious diseases worldwide in 2014 [1]. Brazil is among the 22 countries that account for $80 \%$ of cases, and the state of Rio de Janeiro exhibits one of the worst scenarios in the country, with the highest mortality rate and the second highest incidence in $2014[1,2]$.

Treatment dropout with consequent worsening of the disease is one of the main factors responsible for the current situation. To improve this condition, the tuberculosis control strategy recommended by the World Health Organization (WHO) is the directly observed therapy (DOT). DOT means that a trained health care worker or other designated individual (excluding a family member) provides the prescribed TB drugs and watches the patient swallow every dose [3]. Although DOT is to guarantee the commitment of patients, healthcare professionals and the government to treatment [1], the real effectivity is determined by many complex factors $[4,5]$. In 2014 , the coverage of DOT for new cases of tuberculosis in the state of Rio de Janeiro was 48\% [6]; expansion of DOT coverage is expected to improve the disease indexes via an increase in the cure rate and a reduction of dropouts and deaths.

Even if DOTS regimen is well studied and globally accepted treatment method, in not all countries the treatment shown be costeffective [7]. As the financial burden for implementation of $100 \%$ program is high, the decision is not trivial, nevertheless WHO recommendation. The aims of the present study were to develop a decision-tree model for the cost-effectiveness analysis of DOT for new cases of tuberculosis in Rio de Janeiro and to perform a budget impact analysis of the expansion of DOT coverage for this Brazilian state.

\section{MATERIALS AND METHODS}

A decision tree model was plotted to simulate the stages of tuberculosis treatment for cost-effectiveness analysis of DOT for six months of treatment of 10,000 new cases, considering patients with a weight over $50 \mathrm{~kg}$ and without drug resistance from the state of Rio de Janeiro. The following interventions were compared: (a) selfadministered treatment (SAT), in which patients take their medicines at home and visit a healthcare unit once per month for medical assessment and to receive the medicines, and (b) DOT, in which patients visit a healthcare unit at least three times per week to take their medicines under the supervision of a healthcare professional. In the budget impact analysis, the strategies of (a) DOT with $48 \%$ of coverage of pulmonary tuberculosis cases and (b) DOT with $100 \%$ of coverage were compared.

For the cost-effectiveness analysis, a decision tree was plotted using Tree Age software [8]. The data used in the model were extracted from databases and cost-effectiveness studies $[9,10]$. Health states represent the forms of progression of infection. All individuals included in the cohort were patients diagnosed with active pulmonary disease without drug resistance. After six months of treatment with the basic regimen, five outcomes were considered: (a) treatment success; (b) treatment failure; (c) treatment dropout; (d) death due to tuberculosis-related complications; and (e) deaths due to other causes. 


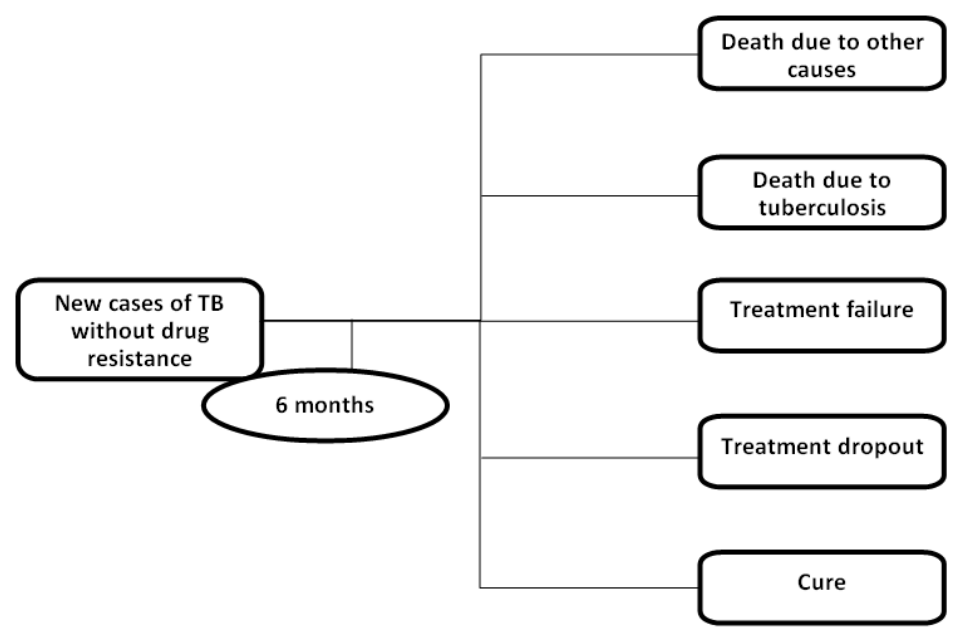

Fig. 1: Progression and outcomes of non-drug-resistant tuberculosis

The following assumptions were considered in the construction of the decision model: (a) the patients included were diagnosed with active tuberculosis without resistance to any anti-tuberculosis drug; (b) a higher adherence to treatment would result in a larger number of individuals cured and a lower dropout rate; (c) cases of spontaneous cure following treatment dropout were not considered; (d) non-notified cases, false-negative cases and diagnosed patients who had not started treatment were not considered; (e) the cost of implantation and management of DOT at healthcare units was not considered; and (f) direct medical costs related to medicines, human resources and testing for tuberculosis treatment were considered.

\section{Probabilities}

Probabilities were estimated based on epidemiological data provided by the Health Ministry [2-5, 11-12]. Average percentages for the period of 2007-2014 were calculated for the following outcomes: treatment dropout, death due to tuberculosis and death due to other causes (table 1). These percentages were considered as probabilities, and the same value was used for the treatment failure outcome, as it is not associated with the DOT and SAT strategies [9].
The variable treatment time (TT), namely, the average number of months of treatment over the six-month period, was used to calculate the cost of medicines, testing and human resources. For the cure and treatment failure outcomes, the time corresponded to the full time period of the basic regimen.

Costs

The unified health system (Sistema Único de Saúde-SUS) perspective was adopted for the analysis. The direct medical costs considered were divided into three categories: medicines, human resources involved in the care of tuberculosis patients with or without DOT and post-diagnosis tests.

The medicines employed in each regimen and the treatment time recommended in the protocol established by the Health Ministry were used in the calculations [11]. All values were obtained through request via the Health Ministry information access site [13].

According to the treatment protocol for new cases of tuberculosis established by the Health Ministry, a six-month course of treatment with the basic regimen resulted in a cost of BRL 155.28 for medicines (table 2).

Table 1: Probabilities and treatment time of outcomes for tuberculosis with and without DOT

\begin{tabular}{llllll}
\hline Probabilities & SAT (\%) & TT (months) & DOT (\%) & TT (months) & References \\
\hline Cure & - & 6 & - & 6 & {$[6]$} \\
Dropout & 16 & 4 & 14 & 4 & {$[6]$} \\
Death due to tuberculosis & 4.2 & 3 & 2.4 & 3 & {$[6]$} \\
Death due to other causes & 2.8 & 3 & 2.1 & 4 & {$[6]$} \\
Failure & 2 & 6 & 2 & 6 & {$[6]$} \\
\hline
\end{tabular}

DOT: directly observed therapy; SAT: self-administered treatment; TT: treatment time in months

Table 2: Cost of medicines for 6 mo of treatment with the basic regimen

\begin{tabular}{|c|c|c|c|c|c|}
\hline Medicines/dose & Unit value (BRL) & Tablets/day & TT (days) & Medicines total cost & References \\
\hline RHZE (150/75/400/275 mg) & 0.3816 & 4 & 60 & 91.584 & [9] \\
\hline RH $(150 / 100 \mathrm{mg})$ & 0.1327 & 4 & 120 & 63.696 & [9] \\
\hline Total cost of treatment with the basic regimen & - & - & 180 & 155.28 & - \\
\hline
\end{tabular}

RHZE: rifampicin, isoniazid, pyrazinamide and ethambutol; RH: rifampicin and isoniazid; TT: treatment time

Both the approach and the cost of human resources were considered based on data from public health care units in Rio de Janeiro, as in the studies by Steffen et al. (2010) and Mohan et al. (2007) [10, 14]. As tuberculosis treatment and DOT supervision occur within the opening hours of the health basic units, DOT does not involve additional costs related to structure, only those related to human resources. The salary of the professionals charged with medical care and observation of medicine intake, i.e., nurses or nursing technicians, was considered in the estimation of the relationship between time spent by employees in the analysed activity and the resources spent. In the present study, supervision was performed five times per week for two months and three times per week for four months, resulting in a total of approximately 88 incidences of supervised medicine intake [10, 14]. Following salary readjustment according to the table for municipal employees in Rio de Janeiro [15-20], the cost was BRL 481.04 and BRL $1,847.82$ for SAT and DOT, respectively. 
The cost of post-diagnostic testing was obtained from the SUS System of Management from the table for Procedures, Medicines and OPM (orthoses, prostheses and materials) [13]. In the basic regimen, for cases of pulmonary tuberculosis, the Health Ministry recommends bacilloscopy of sputum once per month. The cured patients thus underwent sputum bacilloscopy six times, with a cost of BRL 25.20. In addition, patients who experienced treatment failure were also subjected to investigation for acid-fast bacilli (AFB) and an antibiogram for mycobacteria, with a total expense of testing of BRL 44.16 .

The resources allocated per patient represents the total sum of expenses for medicines, human resources and testing. Patients cured after treatment with the basic regimen consumed resources for a period of six months; the cost of treatment when SAT was applied was BRL 662.00, and the cost with DOT was BRL 2.028.00. Therefore, the patients subjected to DOT required three times more resources than those treated with SAT.

\section{Effectiveness}

Broadening of the scope of DOT coverage is intended to reduce the mortality rate of tuberculosis, i.e., to reduce the number of deaths caused by the disease due to lack of treatment. This outcome was measured as the number of lives saved, corresponding to patients cured as a result of the adopted strategy [21-23].

\section{Budget impact}

The budget impact analysis was performed by considering a broadened coverage of DOT for new cases of pulmonary tuberculosis without drug resistance. The coverage was thus increased from $48 \%$, i.e., the scope in 2014 , to $100 \%$, which is the ideal goal established by the National Programme of Tuberculosis Control (Programa Nacional de Controle da Tuberculose) for high-priority municipalities [24].

\section{RESULTS}

\section{Effectiveness}

The effectiveness of tuberculosis treatment was measured as the number of cured patients. Simulation of DOT for $100 \%$ of a cohort composed of 10,000 new cases of tuberculosis without drug resistance subjected to the six-month basic regimen resulted in 180 fewer deaths than that of SAT and 22 fewer deaths than the current DOT coverage, $48 \%$. In addition, DOT with $100 \%$ coverage resulted in an additional 420 instances of cure compared to SAT and 218 additional instances of cure compared to SAT with $48 \%$ coverage. One additional benefit was 171 fewer cases of treatment dropout. These values are comparable to those obtained in studies conducted in Belém, Pará state, Brazil, and in Peru [23,25].

\section{Cost-effectiveness analysis}

DOT with the current coverage is preferable to DOT with $100 \%$ coverage, as the incremental cost-effectiveness ratio (ICER), BRL 30,454 per cured patient in Rio de Janeiro relative to new cases of tuberculosis without drug resistance, was similar in both cases. Therefore, this situation is preferable to any proportional combination of DOT and SAT. Table 3 describes the values obtained in the simulation.

Table 3: Cost-effectiveness analysis of the basic regime for $100 \%$ DOT and SAT for 10,000 individuals

\begin{tabular}{llllll}
\hline Strategy & Cost (R\$) & Effectiveness (cured patients) & IC (R\$) & IE(cured patients) & ICER(BRL/cured patients) \\
\hline SAT & $6,280,486.00$ & 7,533 & - & - \\
DOT $(100 \%)$ & $19,068,209.00$ & 7,953 & $12,787,723.00$ & 420 \\
\hline
\end{tabular}

SAT-self-administered treatment; DOT-directly observed therapy; IC-incremental cost; IE-incremental effectiveness; ICER-incremental costeffectiveness ratio

\section{Sensitivity analysis}

To determine which variables exerted a greater impact on the results obtained, a tornado diagram was plotted for the first decision tree model of total costs (fig. 2). The costs of medicines (rifampicin, isoniazid, pyrazinamide and ethambutol (RHZE) and rifampicin and isoniazid (RH)) were increased or decreased by $20 \%$, along with the costs of sputum bacilloscopy and the human resources expenses involved in DOT. Human resources were practically the only factor that accounted for the variation of costs, but it did not significantly impact the final result.

Tornado Analysis (Net Benefits)
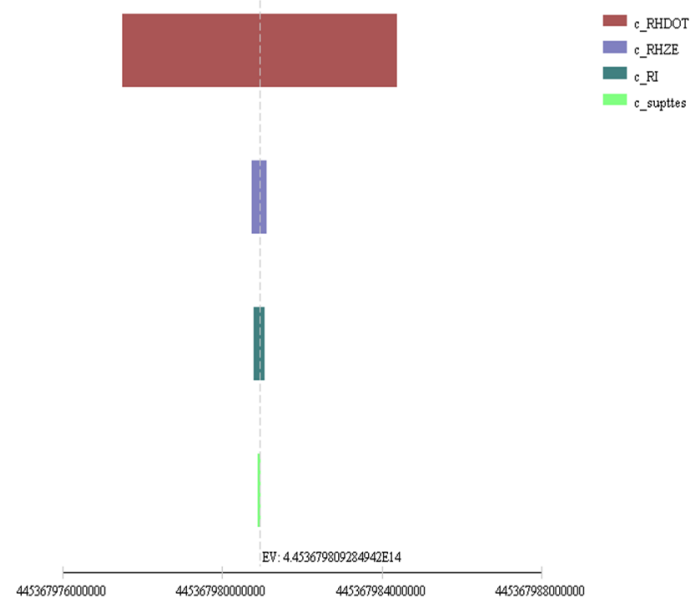

Fig. 2: Tornado diagram representing the total cost of treatment of 10,000 individuals
Source: the authors. c_HRDOT: cost of human resources involved in DOT, c_RHZE: cost of treatment with the RHZE combination, c_RI: cost of treatment with the RI combination, c_Sputtest: cost of sputum bacilloscopy

Variation of probabilities was performed only for the probability of cure with DOT and SAT. The minimum value was $90 \%$ of that used in the model, and the maximum value was the goal recommended by the WHO, i.e., $85 \%$ cure rate $[1,25-26]$. The tree was plotted so that the probabilities of cure, treatment dropout and death due to tuberculosis were proportionally related, i.e., an increase in the cure rate would reduce treatment dropout and deaths due to tuberculosis. This analysis revealed an impact of approximately $8 \%$ on the ICER, with no changes in the previously obtained result.

The cost of human resources when DOT was applied and the probability of cure with DOT were the variables that most influenced the total cost and ICER, while the cost of medicines and sputum bacilloscopy exerted less influence. The sensitivity analysis showed that even when the cost of the human resources involved in DOT varied, the ICER interval, BRL 37,000-BRL 65,000, showed the robustness of the result.

\section{Budget impact analysis}

In this analysis, the following strategies were compared: (a) the current scenario, i.e., DOT coverage of $48 \%$, and (b) the ideal goal, i.e., $100 \%$ coverage. New cases of pulmonary tuberculosis in Rio de Janeiro were included.

Broadening of DOT coverage from the current $48 \%$ to $100 \%$ in a cohort of 10,000 new cases of tuberculosis per year was associated with an incremental cost of BRL 6,651,330.00 (USD 1,911,301.72) in the simulation performed in the present study.

\section{DISCUSSION}

Two studies that conducted a cost-effectiveness analysis of DOT performed in healthcare units in Rio de Janeiro rated DOT as a cost- 
effective strategy $[9,13]$. In Monhan et al. (2007) study, the ICER for DOT was USD 300 per case averted, USD 3,270 per death averted and USD 86 per disability-adjusted life year (DALY) saved [9]. To Steffen et al. (2010), the ICER was USD 6,616 per completed DOT treatment [13]. Studies conducted in Ecuador and Haiti suggest that implementation of DOT would result in benefits for the government and society after a 20 -year period $[21,22]$. Other studies did not find any benefits justifying implementation of DOT to combat tuberculosis. In one cost-effectiveness analysis performed in Pakistan from the societal perspective, DOT supervised by professionals was the least cost-effective strategy (USD 310 per cured case), and SAT the most cost-effective strategy (USD 164 per cured case). In contrast to the WHO expectations and recommendations, that study did not find any improvement in the cure rates with DOT and indicated that the opportunity costs associated with visits to healthcare facilities to receive treatment (required in this strategy) might behave as a barrier against the completion of treatment [7].

To expand DOT coverage exclusively for new cases of non-drugresistant tuberculosis from the current $48 \%$ to $100 \%$, the government of the state of Rio de Janeiro must spend approximately BRL 6,700,000.00 (USD 1,90,000.00). This amount represents 3\% of that spent in 2015 (USD 65,000,000.00) in Brazil for non-drugresistant tuberculosis and $4 \%$ of the resources (USD 47,000,000.00) that the government needs to invest to combat non-drug-resistant tuberculosis [1]. Considering that Rio de Janeiro accounted for $15 \%$ of the new cases of tuberculosis in Brazil in 2012 [2], such an investment might be considered by health managers.

The main limitations of the present study derive from the fact that it did not consider the secondary benefits of treatment, such as reduction of transmissibility, or the instances of relapse and retreatment. In addition, the data for probabilities were procured from governmental databases, which may be subject to distortion related to the quality of information, underreporting or duplicate records.

In addition, because the perspective of the health system was adopted, the costs for patients and their relatives were not considered. Both the structural costs associated with DOT implantation and training of the involved professionals nor the costs of other medications also used, especially in severe and drugresistant cases, were considered.

Finally, the results of the present study cannot be extrapolated to other, more narrowly-focused populations, e. g., patients coinfected with human immunodeficiency virus (HIV)/acquired immunedeficiency syndrome (AIDS), or to other healthcare systems based on reimbursement or payment.

\section{CONCLUSION}

The analysis performed showed that supervised therapy might be a cost-effective strategy for the treatment of new cases of pulmonary tuberculosis in the state of Rio de Janeiro. However, expansion of DOT coverage might not suffice to attain the goals of an $85 \%$ cure rate and $5 \%$ treatment dropout established by the WHO without a clear understanding of the flaws and obstacles that this strategy must overcome. Therefore, rather than broadening coverage, reformulation of the social and economic policies included in the programme is more relevant, in addition to supervision of the units that perform DOT and thorough revision of the full process.

In addition to being cost-effective, broadening the coverage of DOT for new cases of tuberculosis in Rio de Janeiro would fit within the government's budget. Approximately $15 \%$ of the new cases of tuberculosis in Brazil occur in Rio de Janeiro [2], while the expansion of DOT coverage to $100 \%$ in this state would require $4 \%$ of the resources estimated by the Brazilian government to combat nondrug-resistant tuberculosis.

Reduction of the number of deaths represents an adequate incentive for the government of Rio de Janeiro to consider investing in the expansion of a strategy to combat tuberculosis, as it was the Brazilian state with the largest number of deaths due to this disease in 2014.

\section{ACKNOWLEDGEMENT}

We would like to thank our colleagues at the Laboratory of Statistics and Mathematics Applied to Health (Laboratório de Estatística e Matemática Aplicada a Saúde-LEMAS) of the Institute of Social Medicine (Instituto de Medicina Social), State University of Rio de Janeiro (Universidade do Estado do Rio de Janeiro-UERJ) for their material, intellectual and human support.

\section{AUTHORS CONTRIBUTION}

Cid M. de M. Vianna and Gabriela B. G. Mosegui were the principal investigators for the economic evaluation. Ana Carolina Machado Russo de Moura supervised the economic evaluation activities. Benedito Cordeiro led the efforts to determine drug effectiveness. Gabriela B. G. Mosegui conceived the idea for this paper. Gabriela B. G. Mosegui, Cid Manso de Mello Vianna and Ana Carolina Machado Russo de Moura wrote the first draft of this manuscript, which was edited and proof read by all other authors. All authors read and approved the final manuscript.

\section{CONFLICT OF INTERESTS}

The authors declare that there is no conflict of interest concerning the content of the present study

\section{REFERENCES}

1. World Health Organization. Global tuberculosis report; 2016. Geneva: World Health Organization. Available from: http://www.who.int./tb/publications/global_report/gtbr2016. [Last accessed on 29 Jul 2017]

2. Brasil. Ministerio da Saude. Situaçao Epidemiologica. Dados da tuberculose. Available from: http://portalsaude.saude.gov.br/index.php/o-

inisterio/principal/leia-59 mais-o-ministerio/741-secretariasvs/vigilancia-de-a-a-z/tuberculose/11485-situacaoepidemiologica-dados. [Last accessed on 14 Jan 2017]

3. Minnesota Department of Health. TB Prevention and Control Program. Available from: http://www.health.state.mn.us/ divs/idepc/diseases/tb/lph/dot.html. [Last accessed on 30 Jun 2017]

4. Khairunnisa AN. Pharmacists' perception about their roles in tuberculosis control program in medan, Indonesia. Asian J Pharm Clin 2017;10:256-8.

5. McLaren ZM, Meyer AJ, Sharp AR. Does directly observed therapy improve tuberculosis treatment? More evidence is needed to guide tuberculosis policy. BMC Infect Dis 2016;16:537.

6. Brasil. Ministerio da Saude. Sistema de informaçao de agravos de notificacao. Available from: http://sistemas.saude. rj.gov.br/tabnet/deftohtm.exe?sinan/tuberculose.def/. [Last accessed on 10 Feb 2017]

7. Khan MA, Walley JD, Witter SN, Imran A, Safdar N. Costs and cost-effectiveness of different DOT strategies for the treatment of tuberculosis in Pakistan. Health Policy Plan 2002;17 :178-86.

8. Data version, 1.0.3. Tree Age Software, Inc., Williamstown; 2009.

9. Ferreira V, Brito C, Portela M, Escosteguy C, Lima S. DOTS in primary care units in the city of rio de janeiro, Southeastern Brazil. Rev Saude Publica 2011;45:40-8.

10. Steffen R, Menzies D, Oxlade O, Pinto M, de Castro AZ, Monteiro $\mathrm{P}$, et al. Patients' costs and cost-effectiveness of tuberculosis treatment in DOTS and non-DOTS facilities in Rio de Janeiro, Brazil. PLoS One 2010; 5:e14014.

11. Brasil. Ministerio da saude. Secretaria de vigilancia em saude. Departamento de vigilancia epidemiologica. Manual de recomendacoes para o controle da tuberculose no Brasil. Brasilia: Ministerio da Saude 2011. p. 284.

12. Brasil. Ministerio da saude. Informações sobre tuberculose no Brasil. Available from: http://www.acessoainformacao.gov.br. [Last accessed on 10 Feb 2017]

13. Brasil. Ministerio da Saude. Sistema de gerenciamento da tabela de procedimentos, medicamentos e OPM do SUS. Available from: http://sigtap.datasus.gov.br/tabela-unificada/ app/sec/inicio.jsp. [Last accessed on 06 Mar 2017]

14. Mohan CI, Bishai D, Cavalcante S, Chaisson RE. The costeffectiveness of DOTS in urban Brazil. Int J Tuberc Lung Dis 2007;11: 27-32. 
15. Rio de Janeiro. Decreto $\mathrm{n}{ }^{\circ} 31.261$ de 14 de outubro de 2009 . Dispoe para o exercicio de 2009, sobre o reajuste anual da remuneracao. Diario oficial do municipio do rio de janeiro. Poder Executivo. Ano XXIII 2009;143:3-15.

16. Rio de Janeiro. Decreto ${ }^{\circ} 32.501$ de 7 de julho de 2010. Dispõe sobre o reajuste anual dos servidores municipais, nos termos que menciona. Diário Oficial do Município do Rio de Janeiro. Poder Executivo. Ano XXIV 2010;75:3.

17. Rio de Janeiro. Decreto n ${ }^{\circ} 34.015$ de 21 de junho de 2011. Dispoe sobre o reajuste anual dos servidores municipais, nos termos que menciona. Diario oficial do municipio do rio de janeiro. Poder Executivo. Ano XXV 2011;70:3.

18. Rio de Janeiro. Decreto ${ }^{\circ}{ }^{\circ} 35.806$ de 22 de junho de2012. Dispoe sobre o reajuste anual dos servidores municipais, nos termos que menciona. Diario Oficial do Municipio do Rio de Janeiro. Poder Executivo. Ano XXVI. 2012;66:3.

19. Rio de Janeiro. Decreto $\mathrm{n}^{\circ} 37.459$ de 29 de julho de 2013. Dispoe sobre o reajuste anual dos servidores municipais, nos termos que menciona. Diário Oficial do Município do Rio de Janeiro. Poder Executivo. Ano XXVII. 2013;91:3.

20. Rio de Janeiro. Decreto $\mathrm{n}^{\circ} 38.878$ de 2 de julho de 2014. Dispoe sobre o reajuste anual dos servidores municipais, nos termos que menciona. Diario Oficial do Município do Rio de Janeiro. Poder Executivo. Ano XXVIII. 2014;73:3.

21. Oxlade O, Vaca J, Romero E, Schwartzman K, Graham B, Hernandez $\mathrm{L}$, et al. The long-term health and economic benefits of DOTS implementation in Ecuador. Can J Public Health 2006;97:14-9.

22. Jacquet V, Morose W, Schwartzman K, Oxlade O, Barr G, Grimard F, et al. Impact of DOTS expansion on tuberculosis related outcomes and costs in Haiti. BMC Public Health 2006;6:209.

23. da Paz, LNF, de Oliveira Ohnishi MD, Barbagelata CM, et de Arruda Bastos F. Efetividade do tratamento da tuberculose. J Bras Pneumol 2012;38: 503-10.

24. Brasil. Ministério da Saude, Secretaria de Politicas de Saude, Departamento de Atencao Basica. Manual tecnico para o controle da tuberculose: cadernos de atencao basica. Ministerio da saude, secretaria de politicas de saude, departamento de atencao basica. 6 ed. Rev e ampl. Brasilia: Ministerio da Saude; 2002. p. 62. Available from: http://bvsms.saude.gov.br/ bvs/publicacoes/guia_controle_tuberculose.pdf. [Last accessed on 15 Jun 2017].

25. Suarez PG, Watt CJ, Alarcon E, Portocarrero J, Zavala D, Canales $\mathrm{R}$, et al. The dynamics of tuberculosis in response to $10 \mathrm{y}$ of intensive control effort in Peru. J Infect Dis 2001;184:473-8.

26. Chrispim PPM. Uma contribuicao para a discussao sobre avaliacaes de programas de controle da tuberculose. Tese (Doutorado em Ciencias na area de saude Pública) Fundacao Oswaldo Cruz. Escola Nacional de Saude Publica Sergio Arouca. Rio de Janeiro; 2011. p. 138.

\section{How to cite this article}

- Ana Carolina Machado Russo De Moura, Gabriela Bittencourt Gonzalez Mosegui, Cid Manso De Mello Vianna, Benedito Carlos Cordeiro. Cost-effectiveness analysis of directly observed therapy for tuberculosis and its expansion in rio de janeiro. Int J Pharm Pharm Sci 2017;9(10):171-175. 